\title{
Makro İktisatta Teorik Arayışlar
}

\section{Theoritical Seekings in Macroeconomics}

\author{
Emre ÖRÜN ${ }^{1} \odot$
}

\section{Öz}

Dinamik stokastik genel denge (DSGD) modelleri küresel finansal krize kadar baskınlığını korumuştur. Bazı iktisatçılar artık makro iktisadın olgun bir bilim olduğunu belirtirken; karşıt taraftaki iktisatçılar DSGD temelli makro iktisadın sonunun geldiğini ifade etmişlerdir. Her ne kadar iki görüşün kesin doğruluğu söz konusu olmasa da gerçek dışı varsayımlar üzerine temellenen ve iktisadi bir krizin olma intimalini göz ardı eden makro iktisat teorilerinin geçerliliği küresel finansal kriz ile sorgulanmıştır. Bu çalışmanın konusu, makro iktisadın küresel finansal krizden teorik temelde nasıl etkilendiğini araştırmaktır. Çalışmanın amaçlarından ilki, DSGD modellerinin günümüzde ne kadar geçerli olduğunu tespit etmeye çalışmaktır. Çalışmadaki bir diğer amaç ise makro iktisadın küresel finansal krizi öngörmede nerede hatalı olduğunu ve eksik taraflarının neler olduğunu tespit etmektir. Çalışmada makro iktisat teorisinin küresel finansal krizden hem teorik hem de iktisat politikası açısından nasıl etkilendiğini ve hangi konularda fikir ayrılıklarının olduğunu tespit etmek için literatüre yön veren çalışmalar incelenmiştir. Buna göre, DSGD modellerinin krizi öngörmede yeterli olmadığı ve finansal krizi atlatmak için hem geleneksel olmayan para politikası araçlarının kullanılması hem de maliye politikasına intiyaç olduğu söylenebilir

Anahtar kelimeler: Dinamik stokastik genel denge, Para politikası, Maliye politikası

JEL Sınıflaması: E00, E32, E44, E52, E58, E62

\section{ABSTRACT}

Dynamics stochastics general equilibrium (DSGE) models are dominant until the 2008 global financial crisis. Although some economists have stated that macroeconomics is a mature science, others believe that macroeconomics that is based on DSGE models has come to its end. Although these opinions are not true, the validity of macroeconomic theories that are based on unreal assumptions and ignore the probability of financial crisis have been questioned during the global financial crisis. This study investigates how macroeconomics has been affected

${ }^{1}$ Araștırma Görevlisi, Yozgat Bozok Üniversitesi, İktisadi ve Idari Bilimler Fakültesi, İktisat Bölümü, Yozgat, Türkiye

ORCID: E.Ö. 0000-0002-2739-1959

\author{
Sorumlu yazar/Corresponding author: \\ Emre ÖRÜN, \\ Yozgat Bozok Üniversitesi, İktisadi ve İdari \\ Bilimler Fakültesi, İktisat Bölümü, Yozgat, Türkiye \\ E-posta/E-mail: emre.orun@yobu.edu.tr \\ Başvuru/Submitted: 30.09 .2020 \\ Revizyon Talebi/Revision Requested: \\ 25.11.2020 \\ Son Revizyon/Last Revision Received: \\ 25.11.2020 \\ Kabul/Accepted: 26.11 .2020
}

Atıf/Citation: Örün, E. (2020). Makro iktisatta teorik arayışlar. İstanbul iktisat Dergisi - Istanbul Journal of Economics, 70(2), 453-479. https://doi.org/10.26650/ISTJECON2020-803096 
by the global financial crisis on a theoretical basis. The first aim of this study is to determine how valid DSGE models are currently. Another purpose of this study is to find out why macroeconomics failed to predict the global financial crisis and the inadequacies of macroeconomics. Relevant studies have been examined to determine how "macroeconomic theories" has been affected by the financial crisis from both theoretical and economic policy perspectives and issues that economists have different opinions on. In this context, it can be said that DSGE models were not sufficient to predict the financial crisis, and it is essential to use unconventional monetary and fiscal policies to overcome a financial crisis.

Keywords: Dynamics stochastics general equilibrium, Monetary policy, Fiscal policy

JEL Classification: E00, E32, E44, E52, E58, E62

\section{EXTENDED ABSTRACT}

What is wrong in economics or economic policies? The latest 2008 global financial crisis has proved that something is wrong in economics, especially in macroeconomic theory. During the crisis, the DSGE could not explain why the crisis happened and what should be done during the crisis. Therefore, a few problems have emerged in economic theory: (i) What kind of new ideas are needed in economics? (ii) What should be eliminated from economic theory? (iii) Is there a need for a new benchmark model? If so, how should it be? (iv) Will there be a change in paradigm? ( $v$ ) How should the new models be used? (Vines $\&$ Wills, 2018).

The effects of the global financial crisis on macroeconomic theories, which is the main subject of this study, have been investigated. Benchmark model has founded conflicting unpleasant assumptions about firms and consumers. Some assumptions, such as the representative agent, have been questioned in economics, so more realistic assumptions, such as the heterogeneous agent, that interact with each other should be developed (Blanchard, 2018; Colander et al. 2008). Although these assumptions may be more simplified, they have to be coherent with reality. Another reason for the failure of the DSGE model is its commitment to the representative rational agent with rational expectations. Moreover, the financial market and behavior of the agent are ignored in the model, which is another reason for the criticism of the DSGE models (Stiglitz, 2014). The ignoring of financial markets in macroeconomic theories and having a 
rational agent in DSGE models have not been only reason of financial crisis. According to Krugman (2018), another reason why the models failed to predict the global financial crisis is that they ignore macroeconomics data. Krugman (2018) stated that adding finance and financial frictions to macroeconomics is meaningful, but understanding the price dynamics is important in DSGE models.

What have we learned from the global financial crisis? After the global financial crisis, agent-based computational economics and complexity economics have been understood as new alternative theories in macroeconomics. Moreover, the complex structure of the financial system and financial improvements have become important in macroeconomics, especially in the development of new theories (Blanchard \& Summers, 2017). According to Blanchard and Brancaccio (2019), the following lessons should be learned from the financial crisis:

- The first lesson is about the financial system. The role of the financial system in the economy has been very simplified, so many macroeconomic models have not been used to analyze the financial sector; this is a problem.

- The second lesson is that different economic policies should be used to control the financial system and avoid risks.

- The third lesson is about regulation. When a regulation is implemented, people try to find deficiencies in the regulation. Moreover, the successful implementation of a regulation takes time. Therefore, policymakers should be careful when implementing a regulation.

- The fourth lesson is that when crisis hit economies, they fluctuate around the trend and return to equilibrium on their own. The view that the economy is stable is wrong.

- The last lesson from the global financial crisis is about the rise of populism. Economic insecurity and the rise in inequality are the main cause of populism.

The global financial crisis has raised these questions: What do we expect from the benchmark models? How should economics education be carried out? Should it be simple? It can be simplified, but it should not be away from realities. Moreover, it has been proved that unorthodox monetary policies should be used 
to overcome a financial crisis. Therefore, quantitative easing, forward guidance, and zero lower bound have been frequently used as monetary policy tools. Although, different monetary policy tools have been used during the crisis, it has not enough to use them alone. Fiscal policy should be implemented with monetary policy during a financial crisis. Fiscal policy has a different way of reducing the effect of economic depression and ensuring income distribution, which is the main reason why fiscal policy is used. 


\section{Giriş}

İktisattaki temel değişim "Büyük Buhran" ile başlamıştır. Büyük buhrana bir cevap niteliği taşıyan Genel Teori'de John M. Keynes, Marshallgil iktisadın yeterli olmadığını belirtmiş ve böylece makroekonomi politikasına müdahaleci yaklaşım girmiştir. Bununla birlikte F. Hayek ise bunun ne mümkün ne de gerekli olacağını belirtmiştir (Vines ve Wills, 2018, s. 2). Neredeyse bir yüzyıl sonra küresel finansal kriz meydana gelmiş ve makro iktisatçıların hem ehliyet hem de alçak gönüllü olma açısından eksik olduğu ortaya çıkmıştır. Krizin bir sonucu olarak makro iktisat teorisinin nasıl olması gerektiği net olmamakla beraber iktisat öğrencilerine de ne öğretilmesi gerektiği tartışma konusu olmuştur. Bu bağlamda Büyük Moderasyon (Great Moderation) esnasında Yeni Keynesyen Dinamik Stokastik Genel Denge Modeli (DSGD) bir "Benchmark Model" olmuştur. Bu model, küresel finansal krizin nedenlerini ve kriz esnasında ne yapılması gerektiğini tam açıklayamamıştır. Bu durumda ise iktisatta;

1. Ne tür yeni fikirlere ihtiyaç var?

2. Nelerin çıkarılması gerekmektedir?

3. Yeni "Benchmark Model" neye benzemeli ve nasıl olmalıdır?

4. Bir paradigma değişikliği olacak mı?

5. İktisat eğitiminde yeni modelin kullanımı nasıl olmalıdır?

Sorularına yeterince net bir cevap alınamamış ve tartışılması gereken bir alan olarak iktisatçıların karşısına çıkmıştır. Mamafih, benchmark DSGD modelinin iktisadi amaçlar için uygun olup olmadığı, iktisadi büyümenin daha iyi anlaşılabilmesi için modele ne tür eklemeler yapılması gerektiği, zaman içinde (intra-temporal) önemli komplikasyonların neler olduğu, bahsi geçen soru ve sorunların büyük veya küçük modellerle mi tartışılması gerektiği ve modellerin veri ilişkisinin nasıl olması gerektiği iktisatta cevap aranan konular arasına girmiştir (Vines ve Wills, 2018).

İktisat literatüründe cevap aranan bu tür "sorunsallar", DSGD modellerinin geleceğinin ne olacağı konusunda fikir ayrılıklarına sebebiyet vermiştir. Kimi iktisatçllar DSGD modellerinin artık işlevini yitirdiğini, var olan varsayımların geçerli 
olmadığını ve bu yüzden yeni modellere geçilmesi gerektiğini ifade etmektedir. Diğer taraftaki iktisatçılar ise küresel finansal krizi atlatmada DSGD modellerinin yardımcı olduğunu ve yeni teoriler ile eksikliklerinin düzeltileceğini düşünmekte ve bu bağlamda "DSCD modelleri çekirdek model olmaya devam edecek" görüşünü benimsemektedir (Lindé, 2018).

Çalışmada ikinci bölümde makro iktisat teorisi ile ilgili teorik tartışmalara yer verildikten sonra makro iktisat teorisi bağlamında ne tür dersler çıkarılabileceğine değinilecektir. Üçüncü bölümde para politikası ve maliye politikasının nasıl olması gerektiğine dair teorik tartışmalara yer verilecektir. Sonuç bölümünde ise makro iktisat teorisinin gelişiminin nasıl olabileceği, uygulanan politika araçlarının avantajları ve dezavantajlarına yer verilecek ve genel bir değerlendirme yapılacaktır.

\section{Makro İktisat Teorisinde Çıkmazlar: Teori ve Tartışmalar}

DSGD modeli makro iktisat araştırmalarında baskın role sahip olmuştur ve bazı iktisatçılar makro iktisadın artık olgun bir bilim olduğu görüşünü benimserken, karşı görüşteki iktisatçılar makro iktisadın sonunun geldiği ve geçerliliğini yitirdiği görüşünü savunmaktadır. Ancak her iki görüş de tartışmaya açıktır (Blanchard, 2018).

Benchmark model, krizi öngörmede ve atlatmada Blanchard'a göre (2018) yetersiz kalmıştır. Benchmark model nahoş varsayımlar üzerine temellenmekle kalmamış, ayrıca bu varsayımlar firmalar ve tüketiciler hakkında bildiklerimiz ile uyuşmazlık içindedir. Buradaki temel husus varsayımların basitleştirici unsurundan ziyade gerçeklik ile uyumu söz konusu olmaktadır. Bu bağlamda Colander ve ark. (2008), makro iktisatta daha gerçekçi varsayımların ortaya konulması gerektiğini ileri sürmüş ve temsili ajan fikrinin ne kadar gerçekçi olduğunu sorgulamıştır. Birbiri ile etkileşim içinde olan iktisadi ajanların modellere dâhil edilmesi gerektiğini ve iktisadi ajanlar arasındaki etkileşimin yapısının da incelenmesi gerektiğini belirtmiştir. İktisatta artık mikro temeller (micro foundations) olmadan iktisat yapmanın mümkün olabileceğini ve ayrıca mikro temellere dayalı bir makro iktisat teorisinin geliştirilmesinin "teorisyenlerin" seçeneği olması gerektiğini belirtmiştir. 
Colander ve ark. (2008), bu bağlamda iktisatta "mühendislik yaklaşımının" (engineering approach) kullanılabileceğini ve araştırmacıya esneklik sağlayan VAR (Vector Auto Regression) ya da CVAR (Co-integrated Vector Auto Regression) gibi yöntemlerle de araştırma yapılabileceğini ifade etmiştir. Colander ve ark. (2008) çalışmada elde edilen sonuçların veriden ziyade araştırmacının kararlarına da bağlı olabileceğini belirtmiş ve sonuçların araştırmacıya özel olacağını ifade etmiştir. Bu minvalde, geliştirilen makro iktisat modelleri basitleştirici varsayımlar içerebilir ancak; bunların gerçekler ile uyumlu olması gerektiği açıktır. Bu doğrultuda Stiglitz (2014), bu modellerin başarısız olmasının bir nedeni olarak rasyonel beklentilere sahip, tamamen temsili rasyonel ajan kavramına olan bağlılıktan kaynaklandığını belirtmiştir. Stiglitz'in (2014) bir diğer eleştirisi ise finansal piyasaların ve buradaki iktisadi ajanların davranışlarının göz ardı edilmiş olmasıdır. Stiglitz (2014) var olan DSGD modellerine finansal piyasaların vb. dâhil edilmesinin yeterli olmayacağını ve bu yüzden makro iktisadın yeniden inşasının gerekli olduğunu vurgulamıştır. Stiglitz'e göre (2014) modern makro iktisadın en zorlu konusu merkez bankalarının kullandıkları modellerde bankaların ve finansal piyasaların bir role sahip olmamasıdır. Mamafih, benchmark modeli tahmin açısından değerlendirildiğinde, Bayesyen tahmin ve kalibrasyonun karışımı olan standart tahmin yöntemi ikna edici değildir (Blanchard, 2018).

Modeller normatif amaçı kullanılmakla beraber elde edilen normatif çıkarımlar da ikna edici nitelikte değildir. DSGD modelindeki bir başka zorluk/çıkmaz tam bu noktadadır. Bununla birlikte kurulan modellerin amaçları konusuna değinen Caballero (2010), makro iktisadın nihai amacının heterojen iktisadi ajanlar arasındaki etkileşimlerden kaynaklanan derneşik sonuçların ya da iktisadi dalgalanmaların açıklanması gerektiğini belirtmiştir. İktisadı, merkez ve periperi olarak ayıran Caballero (2010), bu durumu ne çekirdek ne de periperi tarafın tam anlamı ile açıklayamadığını belirtmiştir'. Caballero (2010)'a göre makro iktisadın periperi tarafı, kayda değer makro iktisadi olayların anlaşılmasında merkeze göre daha faydalı ve yararlı olmuştur. Finansal ve ekonomik krizler bağlamında periperi

\footnotetext{
1 Periperi iktisadı alt problemler ve mekanizma/tekniklere odaklanmıştır ve karmaşık ve belirsiz (distant) genel denge etkileşimlerini önemsiz bulmuştur. Çekirdek model, genel denge etkileşimlerinin çeşitliliğine odaklanmış ve alt problemleri önemsememiştir.
} 
makro iktisadı spekülatif balonlar, kaldıraç çevrimleri, bilanço varlıklarının ucuza ve zararına satışı ve likidite çıkışı gibi finansal olguların temel yapısının anlaşılmasına katkıda bulunmuştur (Caballero, 2010).

DSGD modelleri normatif amaçlar için kullanılabilirken normatif gerektirmeler (normative implication) çok ikna edici değildir. Modellerin mikro temeller üzerine kurulması DSGD için bir güç sağlasa da Gayri Safi Yurtiçi Hasıla'ya (GSYH) ya da GSYH büyümesine odaklanmak refah açısından bir eksiklik yaratabilmektedir (Blanchard, 2018, s. 46). Bu ise DSGD modellerinin refahı ölçmede eksiklikleri olduğunun bir işareti olarak yorumlanabilir. Bu durum iktisattaki derneşiklik problemine de işaret etmektedir. GSYH gibi tek bir değişkenin her şeyi yansıtamayacağı ve derneşiklik kavramı, GSYH gibi hesaplamaların tamamen doğru yapılamayacağına, eksikliklerin de olabileceğine işaret etmektedir. Bununla birlikte GSYH'nin tek bir odak noktası olması sadece refahın ölçülmesini ve değerlendirilmesini etkilemekle kalmamakta, ayrıca gelecek dönemde uygulanacak politikaları da etkileyebilmektedir (Blanchard, 2018, s. 47).

DSGD modelinin yoğun matematik kullanması, eleştiri alan konulardan biri olmaktadır. Bilindiği üzere yoğun matematik ile tahmin yapılmakta ve ekonomideki bozuklukların (distortions) etkisi çeşitli dinamik simülasyonlar aracılığı ile gösterilmektedir (Blanchard, 2018). Makro iktisadın giderek sayısallaşması hem bir soruna çözüm aranması gerektiğini gösterdiği gibi aynı zamanda sorunun kendisi de olabilmekte ve bu ise "tanımlama problemini" işaret etmektedir (Romer, 2016). Geleneksel Keynesyen modellerin eleştirisi bağlamında Lucas ve Sargent (1978), rasyonel beklentilerin "yatay-denklem kısıtlamaları" ile tanımlama problemini çözmede yardımcı olacağını belirtmiş, ancak Romer (2016), tüketici kararlarının nasıl etkilendiğinin tespit edilmesi açısından rasyonel beklentilerin dâhil edilmesinin tanımlama problemini daha da kötüye götürebileceğini ifade etmiştir. Tanımlama probleminin rasyonel beklentiler ile beraber matematiksel çıkarımlarla aza indirilebileceği Lucas ve Sargent (1978) tarafından belirtilmiş, ancak Romer (2016) bunun hiçbir zaman olmadığını ve olamayacağını ifade etmiştir. Romer (2016), makro iktisat teorisinde Lucas ve Sargent (1978) ile varsayımlar konusunda benzer bir düşünceye de sahip olmuştur. Yeni Keynesyen makro iktisattaki 
varsayımların açıklıktan uzak ve güvenilirliğini yitirdiğini belirten Romer, Lucas ve Sargent ile hem fikir olmuştur.

Enflasyondaki bir artış ile beraber işsizlik oranının düşmeyeceğini belirten Romer (2016), bu konuda Lucas ve Sargent (1978) ile hem fikir olmuş; ancak Lucas'ın da bir konuda başarısızlığa uğradığını belirtmiştir. Lucas (2003), makro iktisat teorisinin krizlerin önlenmesi gibi temel bir konuda başarılı olduğunu ve bu tür bir problemin çözüldüğünü ifade etmiş; ancak Romer (2016), küresel finansal krizin ortaya çıkışı ile Lucas'ın dramatik bir hata yaptığını belirtmiştir. Bu bağlamda Romer'in açılamaları göz önünde bulundurulduğunda artık iktisat literatürü ve makro iktisat literatürü açısından tek bir doğrunun olamayacağı ve tartışma ortamının daima olması gerektiği sonucu çıkarılabilir.

Vines ve Wills (2018)'e göre benchmark model 1960 ve 1970'ler sonrası iktisadi olayları açıklamada kullanılabilir; ancak yaşanan son finansal kriz modelin hatalı ve krizi öngörmede yetersiz olduğunu göstermiştir. Bu bağlamda model başarısız olsa da iktisatta bir paradigma değişiminden ziyade benchmark modeline krizleri öngörme açısından neler eklenebilir, amaçlara daha uygun duruma nasıl getirilebilir sorunsalı da gündeme gelmiştir.

Küresel finansal krizin öngörülmesi konusunda Krugman (2018) farklı bir noktaya değinmiştir. Krugman (2018)'a göre krizi öngörmedeki başarısızlığın nedeni, iktisattaki genel anlayıştan ziyade gözlem eksikliği ya da bir başka deyişle verileri göz ardı etmekle ilgilidir. Krugman (2018), finansal sektörün ve finansal friksiyonların, var olan modellere dâhil edilmesini ya da modellere tamamlayıcı olmasını mantıklı bulmakla birlikte, DSGD modellerinde finansal sektörün olmamasının tahmin başarısızlıklarının kaynağı olmadığını belirtmiştir. Bu bağlamda Krugman (2018), temel makro iktisadın işini yaptığını; ancak krizden sonra fiyat dinamiklerinin anlaşılmasındaki hataların tanımlanması ihtiyacının olduğunu belirtmiştir. 


\section{1. Çıkarılacak Dersler: Alternatif Mümkün Mü?}

2008 küresel finansal krizi ile birlikte makro iktisatta geliştirilen teorilere ve kapitalizme karşı yeni bir alternatif mümkün mü? İktisat teorisi alanında geliştirilen yeni teoriler, ajan-bazlı kompütasyonel iktisat, kompleksite iktisadı gibi yeni alanlar iktisatta geleneksel teoriye karşı bir alternatifin olduğunu göstermektedir. Ancak kapitalizme bir alternatifin var olup olmadığı tartışma konusudur. Olivier Blanchard'a göre kapitalizme karşı bir alternatif yoktur. Küresel krizle birlikte iktisadi alanda hem devlet hem de piyasa kombinasyonu yani iş birliği önem kazanmaya başlamış ve piyasa ile devlet arasındaki tamamlayıcılık ön plana çıkmaya başlamıştır (Blanchard ve Brancaccio, 2019). Makro iktisat teorisi ve politikası, küresel finansal krizle birlikte iktisatçılar tarafından yeniden keşfedilmeye başlanmış ve finansal sistemin karmaşık yapısını, finansal gelişmelerin önemini bilhassa iktisadi sisteme krizleri de dâhil eden teorilerin geliştirilmesi önem kazanmıştır (Blanchard ve Summers, 2017).

2008 küresel finans krizi hem ülke ekonomilerini hem de dünya ekonomisinin gidişatını ciddi derecede etkilemiştir ve ülke ekonomilerindeki iyileşme yavaş yavaş başlamışırır. Kriz ekonominin yapısını etkilemekle kalmamış; ayrıca popülizmde de bir yükselişin olmasına sebebiyet vermiştir. Popülizmin yükselmesinde birçok neden bulunmaktadır; ancak temel tetikleyici faktör eşitsizlikteki artıştır. Bu bağlamda düşünüldüğünde küresel finansal krizden çıkartılması gereken beş ders bulunmaktadır (Blanchard ve Brancaccio, 2019).

Çıkarılacak derslerden ilki ekonomideki finansal sistemdir. Küresel finansal krizden önce makro iktisat teorileri finansal sistemin kendisini büyük oranda göz ardı etmiştir. Makro iktisat teorilerinde finansal sistem, fonları ihtiyacı olanlara transfer eden bir sistem olarak görülmüş ve geliştirilen modellerde borsa fiyatları ve getiri eğrisinin (yield curve) belirlenmesi için finansal sistemin rolü çoğunlukla basitleştirilmiştir. Bu bağlamda, birçok makro iktisadi model finansal sektörü analiz edememiş ve bu durum küresel finansal kriz ile birlikte bir problem olarak ortaya çıkmışır. Makro iktisatçllar, ekonomide neler olduğunu ve ekonominin ne yöne gittiğini anlamak için makro iktisadi değişkenlere bakmanın yeterli olacağını ummaktadır. Mikro değişkenler 
açısından inceleme yapıldığında makro iktisatçıların mikro değişkenlerin hepsine bakacak kadar yeterli vakti, yeteneği ve firsatı yoktur. Ayrıca finansal sektörde var olan sorunların ve sektörün ne yöne gittiğinin makro değişkenler ile açılanamaması bir problem niteliği taşıyabilmektedir. Bu bağlamda, makro iktisatçıların bütün değişkenlere ve detaylarına bakması gerektiği "sorunsalı" ortaya çıkmaktadır. Makro ve mikro değişkenlerin hepsine bakılması gerekmektedir ve bu oldukça zor görünmektedir (Blanchard ve Brancaccio, 2019; Blanchard ve Summers, 2017).

Makro iktisadın, finansı gerçekten göz ardı edip etmediğine bakan Reis (2018) American Economic Review (AER), National Bureau of Economic Research (NBER) ve Journal of European Economic Association (JEEA)'da kriz öncesi ve kriz sonrası makro iktisatta yayınlanan makalelerde makro iktisat ve finans içerikli makalelerin sayısının giderek arttı̆ı̆ını belirtmiştir. Bu bağlamda Reis (2018) makro iktisadın finansı göz ardı ettiğine dair olan eleştiriye farklı bir bakış açısı getirmiş; fakat makro iktisadın, makro iktisadi değişkenlerin tahmininde yeterli bir başarı göstermediğini de ifade etmiştir. Reis (2018), ekonomik değişkenlerin tahmini bağlamında tartışılması gereken birçok konu olduğunu belirtse de iktisadi tahminlerin diğer bilimsel alan tahminlerinin çok gerisinde olduğuna dair kanıya ikna olmadığını da belirtmiştir.

Küresel finansal krizden önce iktisadi dalgalanmaların kendi şok ve yayılma mekanizmalarının olduğu görüşü makro iktisatta yaygınlık kazanmıştır. Ülke ekonomilerinin bir kısmının arz, bir kısmının ise talep kaynaklı birçok iktisadi şok veya dalgalanmadan etkilendiği genel kabul görmüş ve baskın politika olarak para politikasının kullanılması gerektiği görüşü yaygınlık kazanmıştır. Ancak küresel finansal krizden sonra para politikasının tek başına yeterli olmadığı ve ayrıca maliye politikasının da kullanılması gerektiği iktisat literatüründe yer bulmaya başlamıştır (Blanchard ve Summers, 2017, s. 12-13). Bu bağlamda küresel finansal krizden çıarılacak ikinci ders, finansal sistemi kontrol altında tutmak ve risklerden kaçınmak için birçok politika aracı kullanılması gerektiğidir. Genel olarak makro iktisat politikaları küçük basit araç setleri olarak görülmekte; ancak herhangi bir krizin atlatılması için daha fazla politika aracı gerekmekte ve bu durum uygulanacak ekonomi politikasının da daha karmaşık bir yapıya bürünmesine sebebiyet vermektedir (Blanchard ve Brancaccio, 2019). 
Üçüncü ders ise regülasyon uygulanmaya başlandığında ortaya çıkacak problem ile başa çıkmaya çalışmaktır. Regülasyonun uygulandığı alan ister finansal piyasa ister başka bir piyasa olsun, kendi amaçlarını en iyi biçimde gerçekleştirmek için regülasyonun açığını bulmaya çalışan birilerinin olacağı aşikârdır. Bu bağlamda bir reform tanıtıldığında ve uygulanmaya başlandığında iktisadi karar birimlerinin buna alışması zaman alacaktır. Bu durum finansal regülasyonların oldukça zor olduğunu ve bir reformun tanıtıldığı andan itibaren tamamen işler duruma gelmesinin zaman alacağını göstermektedir (Blanchard ve Brancaccio, 2019).

Dördüncü ders ise krizden önce özellikle gelişmiş ülkelerde birçok makro iktisatçı, ekonominin bir trend etrafında dalgalandığını ve politika araçlarının ülke ekonomisini bu trend etrafında yakın tutması gerektiğine inanmıştır. Ülke ekonomilerinin bu şekilde istikrarlı olduğu görüşü yanlış olmakla birlikte, çok küçük bir ekonomik dalgalanmanın ya da şokun ekonomi üzerinde ciddi etkileri olabileceği ortaya çıkmışır. Bu bağlamda ekonominin kendi kendine dengeye gelebileceği görüşü yanlış olmakla birlikte, ekonomide bazı şeylerin yanlış gideceğine dair işaretler gelmeye başladığında gerekli makro iktisadi politikaların uygulanmaya başlanması gerekmektedir (Blanchard ve Brancaccio, 2019).

Stiglitz (2014) makro iktisadın yeniden inşasında iktisadi dalgalanmaların kaynağı etkilerinin ve etkilerinin neden bu kadar uzun sürdüğüne dair cevap aranan sorunsallara alternatif modellerin daha iyi olduğunu belirtmiştir;

- Karışıklığın ya da şokların kaynağı nelerdir? Standart modeller dışsal teknolojik şokların olduğu varsayımını yapmaktadır. Ancak şoklar ya da dibe gidişlerin birçoğu insan yapımı olaylardır ve sistem bu tür karmaşaları ortaya çıkarandır. Bu yüzden bu tür şokların sıklığının ve derinliğinin azaltılması imkân dâhilindedir.

- Görünürde küçük olan şokların niçin büyük etkileri olmaktadır? Standart teorilere göre fiyat ve yatırım ayarlamaları ekonomiyi stabilize etmeye yardım etmektedir. Bu durumdan daha ziyade sistem, şokları genellikle artırmakta ve şoklar bulaşıı hastalıklar gibi yayılmaktadır. Bu bağlamda politika yapıcılar için 
temel konu şokların yayılmasını engellemektir. Ancak standart modeller karşılıklı bağımlılığın -küresel çeşitlilik- istikrara katkıda bulunduğunu belirtmektedir. Bu tür bir anlayış, problemi arttırmakta ve riskin yayılmasına neden olmaktadır.

\section{- Ekonomideki kötüye gidişler neden bu kadar uzun sürmektedir? Standart} teoriler ekonomideki kötüye gidişattan neden hızlı bir şekilde çıkılamadığını açıklayamamaktadır. Buradaki temel konu dağılımdır. Eğer piyasalar iyi işlerse tam istihdam sağlanabilir ve borç sorun teşkil etmez. Ancak standart teorilere göre dağılım önem teşkil etmemektedir. Aynı zamanda temel konulardan bir diğeri denge kavramıdır. Temsili ajan dünyası bir kenara bırakıldığında çoklu dengenin olduğu bir model kurulabilir. Hatta çoklu rasyonel beklentiler dengesinin olduğu modeller bile kurulabilir.

Küresel finansal krizden alınan son ders popülizmin yükselmesidir. Blanchard'a göre bunun temel nedeni iktisadi güvensizliğe ek olarak eşitsizlikteki artıştır. En yüksek yüzde 1'lik kesimin gelir dağılımından aldığı payın yüksekliği, yaşanan krizi daha da artırmıştır. Bankacılara ödenen maaşın yüksekliği, finansal krizin merkezinde olmuştur ve farklı ülkelerde farklı rolleri olsa da bütün bu bileşenler krizde var olan gerçek olarak kalmıştır.

Küresel finansal kriz, makro iktisat alanında derslerin çıkarılmasını sağladığı gibi bazı iktisatçılara göre yeni oluşturulacak çekirdek modelin belirli ilkelere sahip olması gerekmektedir. Bu minvalde kullanışılı bir çekirdek model Lindé (2018)'ye göre beş ilke bulundurmalıdır:

- Kurumsal görüş doğrultusunda karşı-olgusal ve alternatif senaryolar olmalıdır.

- Gelecekte uygulanacak politikalar hakkında güvenilir iletişim olmalıdır.

- Kurumsal görüş doğrultusunda tarihi çözümleme yapılmalıdır.

- Tahmin performansı diğer zaman serisi analizlerine göre vasatın çok altında olmamalıdır. Bu durum kredibilitenin inşasında önemli olmaktadır.

- Model yeterince açık ve basit olmalıdır. Bu şekilde modelin temel özellikleri politika yapıcılar tarafından iyi bir şekilde anlaşılmalıdır. 


\section{Para Politikası ve Maliye Politikası: Nasıl Olmalı?}

Konumuz bağlamında bu başlık altında para ve maliye politikalarının nasıl olması gerektiği konuları ele alınacaktır.

\subsection{Para Politikası}

Kriz ülke ekonomilerini vurduğunda, uygulanan para politikası araçlarındaki değişikliklerin birçoğu ve geliştirilen yeni araçlar, krizin hararetli olduğu bir dönemde ortaya çıkmıştır. Bu dönemde ortaya çıkan soru, geliştirilen bu araçlardan ne kadarının kalıcı olduğu ve para politikasının nasıl yeniden inşa edileceği üzerine olmuştur. Bu minvalde faiz oranları üzerinde etkili alt sınırın ne olacağı, merkez bankalarının bilançolarında daralmaya gidip gitmeyeceği ve para politikasının finansal istikrarı da göz önünde bulundurması gerektiği makro iktisatta, para politikası alanında önemli bir konu haline gelmiştir (Blanchard ve Summers, 2017).

Ekonomik dalgalanmaların ülke ekonomilerini ciddi derecede etkilemesi gelecekte de iktisadi dalgalanmaların daha ciddi olabileceği endişesini artırmıştır. Bu bağlamda ilerleyen dönemlerde gerçekleşecek ekonomik kriz riskinin azaltılması için "para politikası alanında ne yapılmalı" sorusu gündeme gelmiştir. Faiz oranları alt sınırda bile olsa Yellen (2016), merkez bankalarının parasal genişleme ve sözlü yönlendirme gibi daha yüksek enflasyon hedefi için daha hırslı politika stratejileri olduğunu belirtmiş; ancak belirtilen bu politikaların yeterliliği iktisat literatüründe tartışma konusu olmuştur (Yellen, 2016; Rogoff, 2016; Blanchard ve Summers, 2017).

Geleneksel olmayan para politikasında sözlü bir yönlendirme söz konusu olduğunda şu an için enflasyon yükseltilmese de yatırımcılara, para otoritesinin enflasyonu gelecekte yükselteceği mesajı verilmektedir (Rogoff, 2016, s. 124). Merkez bankasının sözlü yönlendirmesinin birkaç formu bulunmaktadır. Sözlü yönlendirmenin çeşitlerinden ilki "delphic" ve "odyssean" yönlendirmedir (Campbell ve ark., 2012). Delphic yönlendirme para politikası yapıcılarının ekonomiyi nasıl gördüğünü ve faiz oranlarının nasıl belirleneceğini ifade etmektedir. Bu yönlendirme 
tavsiye niteliğinde olup, gelecekte uygulanacak politikalar hakkında taahhütte bulunmamaktadır. Bu bağlamda delphic yönlendirme merkez bankasının para politikası uygulamasındaki tahmin edilebilirliğini ve etkinliğini artırmaya yönelik bir politika olarak belirtilebilir. Odyssean yönlendirmede ise merkez bankası gelecekteki politika için önceden 'taahhüt' verme eğiliminde olmaktadır. Odyssean yönlendirme, politika faiz oranının sıfır alt sınır seviyesinde ya da bu seviyeye yakın olması ile ilgili olup, merkez bankası politika faiz oranının daha uzun bir süre için düşük kalacağını ifade etmektedir. Bu bağlamda değerlendirme yapıldığında merkez bankasının yönlendirmesi varlık fiyatları aracıllğıyla ekonomiyi etkilemekte ve merkez bankasının sözlü yönlendirme ile ekonomiyi etkilemesi kuruma ve politika yapıcılarına olan kredibiliteyi göstermektedir (Bernanke, 2017; Campbell ve ark., 2012; Swanson, 2017). Politika değişikliğine neden olan özel ekonomik koşulları tanımlayan bir diğer iki yönlendirme nicel yönlendirme ve nitel yönlendirmedir. Nicel yönlendirme, nitel yönlendirmeye göre daha kesin ve daha kanıtlanabilir olduğu için iktisat literatüründe daha fazla kabul görmektedir (Bernanke, 2017). Bir diğer sözlü yönlendirme de duruma bağlı ve zamana bağlı yönlendirmedir. Illke olarak politika düzenlemesi, ülke ekonomisinin durumuna bağlı olarak uygulanmalıdır; ancak duruma bağlı yönlendirme ise gelecekte işlevini yerine getiremeyebilir (Feroli ve ark., 2017). Zamana bağlı politikanın piyasa katılımcıları için kredibilitesinin yüksek olması, uygulanan politikanın daha etkin olmasına sebebiyet vermektedir (Williams, 2016).

Geleneksel olmayan para politikasının en tartışılanı niceliksel gevşemedir. Niceliksel gevşeme, merkez bankasının piyasadaki varlıklarının satın alımını ifade etmektedir (Bernanke, 2017). Niceliksel gevşeme sinyal kanalı (signaling channel) ve portföy denge kanalı (portfolio balance channel) olmak üzere iki kritik kanal aracılığı ile çalışmaktadır. Sinyal kanalı bilhassa merkez bankasının parasal genişleme taahhüdünü verdikten sonra varlık satın alımını gerçekleştirmek ve kısa dönem faiz oranlarını daha düşük tutmak için kullanılmaktadır (Bauer ve Rudebusch, 2013, s. 7-8). Niceliksel gevşemede bu iki kanal arasında ekonomiyi etkileme açısından farklılık bulunmaktadır. Sinyal kanalı gelecekteki politika faizi beklentilerini etkileyerek işlerken, portföy denge kanalı risk primini ve koşulları değiştirerek işlemektedir. İktisat literatüründe niceliksel gevşemenin ne kadar etkin olduğu tartışma konusu olsa da finansal koşullar üzerinde -beklentiler ve 
vade primi açısından- ve kriz sürecinde etkili bir araç olduğunu göstermiştir (Bauer ve Rudebusch, 2013, s. 23-24; Huther ve ark., 2017). Mamafih, niceliksel gevşeme etkin olduğunu gösterse de iktisat literatüründe eleştirilmekle birlikte eleştirilerin haklılığı konusunda tartışmalar devam etmektedir (Bernanke, 2017):

- Ciddi belirsizlik yaratmaktadır. Uzun vadede enflasyonu kontrol altına tutmayı zorlaştırabileceği gibi yapay bir varlık balonu yaratma potansiyeli bulunmaktadır.

- Finansal piyasaları tahrif etmektedir.

- Eşitsizliği artırmaktadır.

- Merkez bankasının sermaye kaybetmesine neden olmaktadır.

Lindé (2018), DSGD modellerinde yatırım ve tüketim kararlarının kısmen ileriye dönük belirlenmesi açısından, sözlü yönlendirme ve geniş ölçekli özel ve kamu varlıklarının satın alımı gibi geleneksel olmayan para politikalarının uygulanmasını başarılı bulmuştur.

Geleneksel olmayan para politikası araçlarından bir diğeri negatif faiz oranıdır. Küresel finansal krizi atlatmak için negatif faiz oranını Japonya ve birkaç Avrupa ülkesi uygulamış ve merkez bankası için uzun dönem faiz oranlarını aşağı çekmek için yeni ve alternatif bir araç olarak görülmüştür. Bernanke'ye göre (2017) negatif faiz oranını uygulayan ülkeler açısından değerlendirme yapıldığında, ekonomiye etkisi düşünüldüğünden daha ılımlı kalmıştır. Ekonomideki nakit dolanımı bahsedilenden/beklentilerden daha az olmuştur. Negatif faiz oranları ile ilgili endişelerden biri bankacılık sisteminin 'sermayesizleşmesi' yönündedir. Bankalar mevduat sahiplerine negatif faiz uygulayamayacağı için kaybı kendilerinin karşılaması gerekmektedir. Ancak Avrupa ve Japonya'daki bankaların kârını negatif yönde etkilediğine dair çok az kanıt bulunmaktadır. Bankaların negatif faiz oranlarının etkisini azaltma yönünde kullanabileceği birkaç yöntemi olduğu gibi merkez bankalarının da negatif faiz oranının bankalar üzerindeki negatif etkisini gidermek için çeşitli yöntemleri bulunmaktadır (Bernanke, 2017).

İktisat literatüründe sıfır alt sınırın ekonomiyi nasıl etkilediği tartışma konusu olmakla birlikte, makro iktisadi istikrar politikaları hakkında da belirsizliğe neden 
olmuştur. Sıfır alt sınııın hükümet harcamaları, kamu açıkları, yapısal reform ve makro iktisadi politikaların uluslararası aktarımı gibi diğer politikalar üzerinde de etkisinin nasıl olduğu araştırma konusu olmuştur (Rogoff, 2016, s. 124). Para politikasında faiz oranının negatif olması, uygulanan politikanın başarısında tartışmaya sebebiyet vermiştir. Brunnermeier ve Koby'ye göre (2018) bankalar tasarruf saiklerine negatif bir faiz uygulamakta gönülsüz olacaklarını ve negatif faiz oranının banka kârlılıklarını ve ödünç vermeyi azaltabileceğini belirtmiştir. Bu durum daha yüksek bir talepten ziyade daha düşük bir talep düzeyinin olmasına neden olacaktır.

Uzun vadeli tahvilleri hedef alan ve Japonya Merkez Bankası (JMB) tarafından tanıtılan getiri eğrisi kontrolü (yield curve control) 10 yıllık tahvil getirisinin sıfır etrafında olmasını hedeflemektedir. Getiri eğrisi kontrolü niceliksel gevşemeye eştir. Getiri kontrol eğrisinin bazı olası avantajları da bulunmaktadır: bunlardan ilki ödünç alma ve yatırım kararlarını doğrudan etkilemesidir. Güvenilir bir getiri hedefi, merkez bankası tarafından uygulanan miktar satın alımlarının azaltılması ile yani niceliksel gevşeme ile beraber uygulanabilir. Mamafih, satın alınacak finansal varlıklar artık sınırlı sayıda olduğunda getiri eğrisi kontrolü etkin bir strateji de olabilmektedir. JMB tarafından uygulanan getiri eğrisi kontrolü ekonomiyi kayda değer derecede teşvik etmiştir (Bernanke, 2017).

Enflasyonun yükselmesinde kullanılabilecek bir diğer alternatif politika fiyat düzeyi hedeflemesidir. Ekonominin durgunlukta olması ve enflasyonun düşük olması durumunda fiyat düzeyi patikasına geri dönüleceğine dair bir taahhüt merkez bankasının daha sonra daha yüksek enflasyon hedefini gerçekleştireceğini ifade etmektedir. Ancak Blanchard ve Summers'a göre (2017) fiyat düzeyi hedeflemesinin bazı durumlarda dezavantajlı olabileceği belirtilmiştir. Ekonomide beklenen ve gerçekleşen çıktı seviyesinin birbirine eşit olduğu potansiyel durumda bir başka deyişle ekonomide çıktı açığı olmadığı durumda enflasyon çok yüksek olabilmektedir. Bu durumda merkez bankası fiyat seviyesi patikasına geri dönmeyi isteyerek; para politikası aracını sıkılaştıııcı yönde kullanacaktır. Ancak burada sıkılaşııııcı para politikası uygulandığında durgunluk riski ortaya çıkacaktır. Bu ise para politikası açııından zor olabileceği gibi güvenilir de değildir (Blanchard ve Summers, 2017, s. 22-23). Bernanke (2017)'nin enflasyon hedeflemesi ve fiyat düzeyi hedeflemesi açısından üç alternatif önerisi vardır; 
- FED'in uyguladığı politika açısından, enflasyonun var olan \%2 hedefinden daha yüksek olması.

- Fiyat düzeyi hedeflemesinin kullanılması.

- Geçici fiyat düzeyi hedeflemesinin kullanılması.

Daha yüksek bir enflasyon hedefinin benimsenmesi daha yüksek enflasyon ortalamasına sebebiyet vereceği için Bernanke (2017) tarafından ilk alternatif dezavantajlı olarak belirtilmektedir. Fiyat düzeyi hedeflemesi ise ilk alternatife göre daha avantajlı olmaktadır. Avantajlarından ilki fiyat düzeyi hedeflemesi fiyat istikrarı amacı ile tutarlıdır ve bu faiz oranı sıfır alt sınırın olduğu periyoda cevap olarak daha uzun süre düşük (lower-for-longer) durumunu ifade etmektedir. Mamafih, Bernanke (2017)'ye göre enflasyon hedeflemesi yaklaşımından fiyat düzeyi hedeflemesine geçiş yapmak, iletişim zorluğuna sebebiyet verebilir. Bu sebepten dolayı Bernanke (2017), üçüncü bir diğer alternatif olarak geçici fiyat düzeyi hedeflemesinin politika aracı olarak kullanılabileceğini önermiş ve geçici fiyat düzeyi hedeflemesinin ekonomik performansı geliştirebileceğini belirtmiş̧ir. Bu politika, fiyat istikrarını devam ettirebileceği gibi aynı zamanda FED açısından bakıldığında iletişim politikasında sadece ılımlı bir değişimi gerektirmektedir. Üçüncü politika önerisi ilk başta daha çekici gelebilir; ancak güvenilirliği açısından daha fazla analizi gerektirmektedir.

Faiz oranlarının sıfır alt sınıra indirilmesi, bankacılık sistemine finansman sağlamak için gerekli düzenlemelerin yapılması ve bankacılık kesimi haricindeki özel sektörün elindeki finansal varlıkların satın alınması, parasal tabanı genişletmekle kalmamış; ayrıca merkez bankasının da görevi hakkında soruları gündeme getirmiştir. Uygulanan bu politikalar merkez bankalarının bağımsızlığının sorgulanmasına neden olmuştur (King, 2019). Bu bağlamda, King (2019)'e göre merkez bankasının, uygulanan politikalar bağlamında bağımsızlığını riske atan üç tehdit bulunmaktadır;

- Çok fazla vaatte bulunma ve merkez bankalarına yönelik beklentinin fazla olması.

- Sıfır alt limitte, para ve maliye politikası arasında kesin bir ayrımın yapılmamış olması merkez bankasının operasyonel bağımsızlığını tehdit etmektedir.

- Merkez bankasının sorumluluğunun artması; bankacılık sisteminin düzenlenmesi sorumluluğu, bağımsızlığı tanımlamayı zorlaştırmıştır. 
Para politikasında araç çeşitlendirmesine gidilse de burada temel teşkil eden konu kredibilite olmaktadır. Kredibilitenin sağlanması durumunda gelecek dönemde daha yüksek enflasyona erişmek mümkün olabileceği gibi aynı zamanda bu amaca ulaşmak daha kolay olacaktır. Bu bağlamda hangi politika aracı seçilirse seçilsin kriz döneminde var olan depresyona karşılık verme kapasitesi kritik bir önem taşımaktadır (Blanchard ve Summers, 2017).

\subsection{Maliye Politikası}

İktisatçılar, karar alıcılar ve analistler küresel finansal krizi atlatmada maliye politikasının nasıl bir rol üstlenebileceğini incelemişlerdir. Bu bağlamda maliye politikasında, kamu borç düzeyi ile iktisadi büyüme arasındaki ilişkinin nasıl ve nedenlerinin neler olduğu, krizden çıkmak için mali çarpanların nasıl rol oynadığı, mali konsolidasyonların ne zaman ve nasıl uygulanması gerektiği ve etkilerinin neler olabileceği, maliye politikasının hedefinin ne olması gerektiği, cevap aranan ve araştırılan sorunsallardan birkaçı durumuna gelmiştir (Roubini, 2019). Küresel finansal krizde maliye politikası, bütçe açığına, borç oranındaki büyük artışa ve borcun sürdürülebilirliğine ilişkin kaygılara rağmen bir stabilizasyon aracı olarak tekrar keşfedilmiştir (Blanchard ve Summers, 2017; Borg, 2019, s. 169).

Küresel finansal kriz maliye politikası ile ilgili iki temel soruyu da gündeme getirmiştir (Blanchard ve Summers, 2017):

\section{1) Maliye politikası bir stabilizasyon aracı olarak nasıl kullanılabilir?}

Buradaki temel konu, maliye politikasının stabilizasyon aracı olmaktan daha öteye gitmesi gerektiğidir. Kriz, iktisat literatüründe çarpanların kompleks yapısının da fark edilmesini sağlamıştır. Bir başka deyiş ile talep ve çıktı üzerinde etkili olması istenen maliye politikasında çarpanın iktisadi çevreye ve mali düzenlemelere de bağlı olduğu fark edilmiştir. 


\section{2) Maliye politikası fazla borcun olduğu; fakat düşük faizli (büyüme oranlarından da düşük) hükümet tahvillerinin olduğu bir ortamda nasıl yürütülmelidir?}

Maliye politikasının nasıl yürütüleceği söz konusu olduğunda sermayenin marjinal getirisi ve güvenli oran, yani kısa vadeli devlet tahvili, arasındaki farklılığı ayırt etmek önem taşımaktadır. Buradaki temel kavram risk olmaktadır. Sermayenin marjinal getirisi riskli olduğu için yatırımcı güvenli orandan daha yüksek bir faiz oranı olduğunda yatıım yapacaktır. Bu bağlamda büyüme oranından daha düşük güvenli oran, büyüme oranının üzerinde olan sermayenin marjinal getirisi ile daha uyumlu olmakla beraber politikanın idame ettirilmesinde de önem taşımaktadır.

Güvenli oranın ekonomik büyümenin altında kalması, hükumetin borç verebileceği anlamına geldiği gibi ayrıca ekonominin, borç/GSYH oranının artmadan canlandırabileceği anlamına da gelmektedir. Borç vermenin ekonomi üzerinde tam olarak ne tür etki yapacağı hakkında tam bir fikir birliği yoktur. Borç vermede bir artış, kısa dönemde daha düşük vergi ve daha yüksek tüketimi sağlar; ancak nihayetinde sermaye birikiminin azalmasına ve ekonomi, dinamik olarak etkin ve çıktı potansiyelde ise sonrasında daha düşük bir tüketime neden olabilir. Ancak, karşı taraftaki zıt görüş ise düşük oran daha yüksek borç vermeye ve refahın da artmasına olanak sağlayabilmektedir. Bu alanda fikir birliğine varılamaması, ülke ekonomisinin ve yapısının da uygulanacak maliye politikasına uygun olması ve diğer politikalarla da uyumlu olması gerektiğini göstermektedir (Blanchard ve Summers, 2017).

Maliye politikasına uygun olması ve diğer politikalarla da stabilizasyon aracı olarak kullanılması söz konusu olduğunda uygulanacak politikalar açısından kemer sıkma politikasının ekonomiyi canlandırmada işe yarayıp yaramadığı da söz konusu olmuştur. Başka bir deyiş ile buradaki temel soru: Ekonomi derin bir resesyonda iken kamu harcamalarının kısılması çıktının artmasına neden olacak mıdır? Bir diğer soru ise kamu harcaması derin resesyondan kurtulmada işe yarayacak mıdır? (Stiglitz, 2014). Stiglitz (2014), kemer sıkma politikasının derin bir resesyondan çıkmaya yardımcı olmadığını belirtmiştir. Avrupa ekonomisinde uygulanan kemer 
sıkma politikası başarılı olmamış ve daraltıcı politikaları daha az uygulayan ekonomiler nispeten daha iyi performans sergilemiştir (Stiglitz, 2014).

Maliye politikası bir stabilizasyon aracı olarak kullanılırken dikkat edilmesi gereken bir diğer konu mali tutumun devam ettirilmesidir. Genişlemeci maliye politikası uygulanırken kamu maliyesinin de konsolide edilmesi gerekmektedir. Buradaki temel konu, küresel finansal krizi atlatmada maliye politikasının ekonomik büyümeyi desteklemesi ve devam eden yüksek işsizliği azaltmak için maliye politikası devredeyken kamu maliyesinin de konsolide olmasıdır. Bu durum ise maliye politikasındaki temel zorluğu işaret etmektedir. Ayrıca krizin etkisinden kurtulmak için otomatik istikrar sağlayıcılar önemlidir; ancak burada borç düzeyinin GSYH içindeki payı önemli olup, borç oranının yüksek olduğu bir ekonomide otomatik istikrar sağlayıcılarının işlevi uzun dönem açısından sınırlı olmaktadır (Borg, 2019, s. 170-171). Maliye politikasının kriz ile birlikte önemli olduğu ortaya çıkmıştır. Ancak kamu ve finans kesiminin maliye politikasının uygulanabilirliğine güvenmesi gerekmektedir. Borç oranının düşük düzeyde olması maliye politikasının yürütülmesinde ve kamu finansmanın uzun vadede sürdürülebilir olmasında mihenk taşı niteliğini taşımaktadır (Borg, 2019).

Küresel finansal krizi atlatmada maliye politikasının rolü önemli olmakla birlikte, maliye politikasının hedefleri neler olmalıdır? Borg (2019)'a göre maliye politikasının üç temel hedefi bulunmaktadır;

- Dağılım

- İstikrar sağlama

• Büyüme

Maliye politikası Borg (2019)'a göre bu üç temel hedefin hepsi ile ilgilenmelidir. Ayrıca kısa vadede ekonomiyi istikrara kavuşturmayı amaçlayan maliye politikasında uzun dönemde de kalıcı büyüme artışııın sağlanması için üç temel hedef önem taşımaktadır. Maliye politikası ekonomiyi istikrara kavuşturmada önemli olmakla birlikte karar gecikmesi gibi kendine özgü problemleri bulunmaktadır. Para politikasında, uygulanacak politika adımlarının belirlenmesi ve bu politikaların uygulanması, maliye politikasına göre çok daha hızlı olmaktadır. 
Bu durum maliye politikası ile para politikasını birbirinden ayıran husustur. Bu bağlamda, maliye politikasında karar gecikmesinin önlenmesi ya da en aza indirilmesi için ekonomide gerekli kurumsal düzenlemelerin ve kurumların oluşturulması önem taşımaktadır (Borg, 2019).

Maliye politikasının durgunlukta nasıl uygulanması gerektiği söz konusu olduğunda üç popüler seçenek öne çıkmaktadır (Perotti, 2019):

Seçenek 1: Kamu harcamalarının kesilmesi ve vergilerin düşürülmesi. Bu minvalde özel yatırım ve tüketim artacak ve bu da GSYH'yi artıracaktır. Mali alanın görmezden gelinerek uygulandığı bu politika mali konsolidasyona işaret etmektedir. Bu tür bir maliye politikasının uygulanması ekonomiyi resesyondan çıkarabilir mi? Bu tür "genişletici mali tasarruflar/konsolidasyonlar" kısa vadede büyüme oranı ile değiş-tokuş/takas içindedir. İsveç, Danimarka, İrlanda ve Finlandiya üzerine araştırma yapan Perotti (2011) ve Perotti (2019), GSYH artış oranı, özel tüketim artış oranı ve özel yatırım artış oranı ile mali tasarruf arasında kısa vadede bir takasın olduğunu, ayrıca başka bir deyiş ile bu tür "genişletici mali konsolidasyonların" farklı ülkeler üzerinde uygulanabilirliğinin şüphe uyandırdığını ifade etmiştir. Roubini (2019) ise erken uygulanan mali konsolidasyonun ekonomide hem borcun hem de açığın artmasına neden olacağı ve durgunluğun derinleşeceğini belirtmiştir. Bu bağlamda düşünüldüğünde mali konsolidasyonun ne zaman uygulanacağı önem taşımaktadır.

Seçenek 2: Kamu harcamalarının geçici olarak artırılması. Durgunluk döneminde politika yapıcıların kullanabileceği bir diğer seçenek de kamu harcamalarının durgunluk bitinceye kadar artırılması ve daha sonra kamu harcamalarının azaltılacağı taahhüdünü vermektir. Ekonominin sıfır alt limitte olduğu durumda çarpan mekanizması sayesinde ve ekonominin kendi mali alan genişliği de göz önünde bulundurularak değerlendirildiğinde bu tür bir maliye politikası uygulanması durgunluktan çıkmak açısından avantajıdır. Bu tür bir maliye politikası ödeme gücünün sağlanması ve sürdürebilirliğin devam ettirilmesi için önemli olsa da verilen taahhüde uyulmaması gibi bir tehlikesi ve dezavantajı da bulunmaktadır. Perotti (2019, s. 187), bütçe hedeflerine ve 
taahhütlerine uyulması açısından ekonomide bu alanda denetleme rolünü üstlenecek "mali konsey" kurulabileceğini ve bu tür sorunların aza indirilebileceğini belirtmiştir.

Seçenek 3: Geçici olarak vergilerin indirilmesi. Vergilerin indirilmesinin, vergi çarpanı aracılığıyla ekonomiye olumlu etki yapması beklenmektedir. Ayrıca, Perotti (2019), vergi indiriminin Pareto anlamda iyileştirici bir yönü varken kamu harcamalarının artırılmasının Pareto iyileştirici olmadığını ifade etmiştir. Vergi indiriminin yukarıda belirtilen avantajı olmasına rağmen gelir dağılımının alt kısmına etkisi olmamaktadır ve bu gelir dağılımında bozukluklara neden olabilmektedir. Bu bağlamda, uygulanacak olan vergi indiriminin nasıl ve ne tür olması gerektiğinin önemini göstermektedir.

Mali teşvik üzerine değinen Lindé (2018), DSGD modellerinin dezavantajlarına rağmen politika yapıcılara oldukça yarar sağladığıı belirtmektedir. Lindé'ye göre stilize edilmiş DSGD modelleri, etkisi uzun süre devam eden likidite sıkışıklıkları açııından mali tetikleyicilerin faydalarını vurgulamada oldukça yararlıdır ve bu tür öngörülerin Blanchard ve Leigh (2014) tarafından da desteklendiğini belirtmiştir (Lindé, 2018).

\section{Sonuç: Küresel Finansal Krizden Ne Öğrendik?}

Makro iktisattaki bu teorik arayışlar, benchmark modelde gerçeklerden uzaklaşmayan varsayımlar ile makro iktisat tahmini ve eğitimi yapılabileceğini ortaya koymuştur. Küresel finansal kriz para politikası ve maliye politikasının uygulanmasında belirgin değişikliklere yol açmıştır (Blanchard, 2017; Stiglitz, 2018).

Küresel finansal krizde para politikasında niceliksel gevşeme, sözlü yönlendirme ve sıfır alt limit yaygın kullanılan araçların başındadır. Kullanılan araçlar sadece ekonominin durumuna göre seçilmemeli; ayrıca hedefe uygun araç seçiminin de olması gerekmektedir. Bu bağlamda değerlendirme yapıldığında ekonomiye bankacılık sektörü aracılığı ile ne kadar çok likidite sağlanırsa sağlansın, finans sektörü yeterince derinleşmemişse ve aşırı kaldıraç söz konusu ise ekonomiye etkisi 
sınırlı olacaktır. Para politikası araçlarının çeşitlenmesinin avantajları olmakla beraber merkez bankasının amacı bağlamında da iktisat literatüründe bir belirsizliğe neden olmuştur. Para politikası araçlarının artması, ekonomiye müdahale kanallarını çoğaltsa da aynı zamanda merkez bankasının sorumluluğunu artırmış ve buna bağlı olarak merkez bankası bağımsızlığı sorununu da karmaşıklaştırmıştır (King, 2019).

Küresel finansal krizde maliye politikasının nasıl bir rol üstleneceği de araştırma konusu olmuştur ve aşağıda belirtilen sorunsalları gündeme getirmiştir;

- Kamu borcu ve iktisadi büyüme arasındaki ilişki nasıldır? Kamu borcunun nedenleri nelerdir? Bu bağlamda yüksek borç ve açıların nedenleri nelerdir?

- Mali teşviklerin ekonomi üzerinde nasıl bir etkisi vardır?

- Mali konsolidasyonlar nasıl ve ne zaman uygulanmalı? Mali konsolidasyonların hızı ne olmalıdır?

- Mali çarpanın ekonomi üzerindeki etkileri nelerdir?

- Mali baskınlık riski var mıdır?

Maliye politikası ile ilgili yapılan çalışmalar değerlendirildiğinde temel konulardan biri nedensellik olmuştur. Yaşanan küresel finansal kriz ile kamu borcu nasıl bir yol izlemiştir? Finans krizi, kamu borcunun artmasına mı neden olmuştur? Kamu borcunun artmasına rağmen krizi atlatmak için maliye politikası karar alıcılar tarafından kullanılmıştır. Maliye politikasında karar gecikmesi olsa da kullanılmasının nedenlerinden biri hem ekonomide durgunluğun etkisini azaltması hem de toplumun gelir dağılımının korunması açısından birçok kanalları bulunmaktadır. Maliye politikasında uygulanan genişletici politikalar etkili olabileceği gibi aynı zamanda bunun süreklilik kazanmayacağına dair kredibilite de önem kazanmıştır. Mali konsolidasyonların uygulanma şekli her ülkenin kendi ekonomik durumuna göre değişebileceği gibi çok erken bir dönemde uygulanması da durgunluğu daha da artıracaktır.

Sonuç olarak, küresel finansal kriz, makro iktisat literatüründe finansal kesime yeterince ağılık verilmediğini ortaya çıkarmıştır. Finansın dâhil edilmesinin yanı sıra, iktisadi ajanların hem sınırlı rasyonaliteye hem de etkileşim içinde heterojen 
bir yapıya sahip olduğu iktisadi modellemeler gerekmektedir. Mamafih, birden çok denge durumunun gözetildiği dinamik bir yapıyı içinde barındıran iktisadi modellere ihtiyaç olduğu aşikârdır. Dinamik bir yapının olması, modellemede tek bir doğrudan ziyade duruma ve koşullara göre değişebilen varsayımları da içermesini gerektirmektedir. Ayrıca, sınırlı rasyonalite, heterojenlik ve birden çok denge durumu gibi kavramları içinde barındıran modellerin geliştirilmesi, makro iktisat teorisinin meydana gelebilecek krizlere karşı daha etkin olmasını sağlayabilecektir.

Teşekkür: Teorik çalışmaları ile bana ışık tutan Prof. Dr. Ercan EREN'e ve değerli katkılarından dolayı Araştırma Görevlisi Gamze KUTLU'ya teşekkür ederim.

Hakem Değerlendirmesi: Dış bağımsız.

Çıkar Çatışması: Yazar çıkar çatışması bildirmemiştir.

Finansal Destek: Yazar bu çalışma için finansal destek almadığını beyan etmiştir.

Peer-review: Externally peer-reviewed.

Conflict of Interest: The author has no conflict of interest to declare.

Grant Support: The author declared that this study has received no financial support.

\section{Kaynaklar/References}

Bauer, M. D. \& Rudebusch, G. D. (2013). The signaling channel for Federal Reserve bond purchases. Federal Reserve Bank of San Francisco Working Paper Series 2011-21.

Bernanke, B. S. (2017). Monetary policy in new era. Peterson Institute for International Economics.

Blanchard, O. (2017). The need for different classes of macroeconomic models. Peterson

Institute for International Economics. Retrieved from https://www.piie.com/blogs/realtime-economic issueswatch/need-different-classes-macroeconomic-models

Blanchard, O. (2018). On the future of macroeconomic models. Oxford Review of Economic Policy, $34(1-2), 43-54$.

Blanchard, O. J. \& Leigh, D. (2014). Learning about fiscal multipliers from growth forecast errors. IMF Economic Review, 62(2), 179-212.

Blanchard, O. J. \& Summers, L. H. (2017). Retihnking stabilization policy: evolution or revolution?. National Bureau of Economic Research Working Paper, 24179.

Blanchard, O. \& Brancaccio, E. (2019). Crisis and revolution in economic theory and policy: Debate. Review of Political Economy, 31(2), 271-287.

Borg, A. (2019). Borç gölgesinde maliye politikası: artık keynesçiliği hâlâ işe yaramaktadır. G. Akerlof, O. Blanchard, D. Romer, \& J. Stiglitz (Ed.). Ne Öğrendik? Kriz Sonrası Makro Iktisat Politikası içinde (Ö. Limanlı, \& E. Kaya, Çev., s. 169-176). Ankara: Efil Yayınevi. 
Brunnermeier, M. K. \& Koby, Y. (2018). The reversal interest rate. National Bureau of Economic Research Working Paper, 25406.

Caballero, R. J. (2010). Macroeconomics after the crisis: Time to deal with pretense-of-knowledge syndrome. NBER Working Paper, 16429.

Campbell, J. R., Evans, C. L., Fisher, J. D. \& Justiniano, A. (2012). Macroeconomic effects of Federal Reserve forward guidance. Brookings Papers on Economic Activity.

Colander, D., Howitt, P., Kirman, A., Leijonhufvud, A. \& Mehrling, P. (2008). Beyond DSGE models: Toward an empirically based macroeconomics. The American Economic Review, 98(2), 236-240.

Feroli, M., Greenlaw, D., Hooper, P., Mishkin, F. S. \& Sufi, A. (2017). Language after liftoff: Fed communication away from the zero lower bound. Research in Economics, 71(3), 452-490

Huther, J., Ihrig, J. \& Klee, E. (2017-075). The Federal Reserve's porfolio and its effect on interest rates. Board of Governors of the Federal System, Finance and Economics Discussion Series, Washington DC, June 2017.

King, M. A. (2019). Kriz sürecinde para politikası: Diplerden tepelere. G. Akerlof, O. Blanchard, D. Romer, \& J. Stiglitz (Ed.). Ne Öğrendik? Kriz Sonrası Makro İktisat Politikası içinde (Ö. Limanlı, \& E. Kaya, Çev., s. 44-52). Ankara: Efil Yayınevi.

Krugman, P. (2018). Good enough for government work? Macroeconomics since the crisis. Oxford Review of Economic Policy, 34(1-2), 156-168.

Lindé, J. (2018). DSGE models: Still useful in policy analysis?. Oxford Review of Economic Policy, 34(12), 269-286.

Lucas, R. E. (2003). Macroeconomic priorities. The American Economic Review, 93(1), 1-14.

Lucas, R. E. \& Sargent, T. J. (1978). After Keynesian macroeconomics. In After the Phillips Curve: Persistence of High Inflation and High Unemployment (pp. 49-72). Federal Rezerve Bank of Boston.

Perotti, R. (2011). The "Austerity Myth": Gain without pain? National Bureau of Economic Research Working Paper, 17571.

Perotti, R. (2019). Durgunlukta maliye politikası. G. Akerlof, O. Blanchard, D. Romer, \&J. Stiglitz (Ed.). Ne Öğrendik? Kriz Sonrası Makro Iktisat Politikası içinde (Ö. Limanlı, \& E. Kaya, Çev., s. 177-190). Ankara: Efil Yayınevi.

Reis, R. (2018). Is something really wrong with macroeconomics?. Oxford Review of Economic Policy, 34(1-2), 132-155.

Rogoff, K. S. (2016). The curse of cash. New Jersey: Princeton University Press.

Romer, P. (2016). The trouble with macroeconomics. Working Paper.

Roubini, N. (2019). Maliye politikası. G. Akerlof, O. Blanchard, D. Romer, \& J. Stiglitz (Ed.). Ne Öğrendik? Kriz Sonrası Makro Iktisat Politikası içinde (Ö. Limanlı, \& E. Kaya, Çev., s. 191-203). Ankara: Efil Yayınevi.

Stiglitz, J. E. (2014). Reconstructing macroeconomic theory to manage economic policy. NBER Working Paper, 20517. 
Stiglitz, J. E. (2018). Where modern macroeconomics went wrong. Oxford Review of Economic Policy, 34(1-2), 70-106.

Swanson, E. T. (2017). Measuring the effects of Federal Reserve forward guidance and asset purchases on financial markets. National Bureau of Economic Research Working Paper, 23311.

Vines, D. \& Wills, S. (2018). The rebuilding macroeconomic theory project: An analytical assessment. Oxford Review of Economic Policy, 34(1-2), 1-42.

Williams, J. C. (2016). Discussion of "Languange after liftoff: Fed communication away from the zero lower bound. New York: Presentation at the US. Monetary Policy Forum.

Yellen, J. L. (2016). The Federal Reserve's monetary policy toolkit: Past, present, and future. Designing Resilient Monetary Policy Frameworks for the Future. Jackson Hole. 
